blood sample could be obtained within 24 h post-exposure. Sputum was induced within 5 days following exposure, and after at least $24 \mathrm{~h}$ more spirometry and bronchial responsiveness testing was carried out and a second blood sample was taken. After 3 months a third blood sample was taken. In serum pneumoproteins and cytokines were assessed.

Results Significant positive associations were found between exposure to fire smoke and respiratory health parameters (respiratory symptoms, bronchial hyper responsiveness, serum pneumoproteins and cytokines) with and without adjustments for smoking, sex, atopy, age and main job exposure.

Conclusions The results suggest that the risk of health consequences of exposure to fire smoke is underestimated in public and occupational health. From a practical point of view, reduction of exposure to fire smoke could be achieved relatively easy when first responders are instructed about these health consequences and how to reduce fire smoke exposure.

\title{
Respiratory effects
}

\section{RESPIRATORY HEALTH IN FIREFIGHTERS}

Frans Greven, ${ }^{1}$ Huib Kerstjens, ${ }^{3}$ Dick Heederik' ${ }^{1}$ Utrecht University, Utrecht, The Netherlands; ${ }^{2}$ Municipal Health Services, Groningen, The Netherlands; ${ }^{3}$ University of Groningen, Groningen, The Netherlands

10.1136/oemed-2011-100382.206

Objectives The aim of the present study was to determine associations between respiratory health and exposure to smoke of fires.

Methods The studies comprised 3 subsequent stages. First, all active firefighters of the municipal fire brigades of 3 provinces in the Netherlands were invited to fill in a webbased questionnaire. Second, a randomly chosen subset of 402 firefighters underwent spirometry and methacholine provocation, and blood samples were taken to assess atopy and serum pneumoproteins. Third, 51 exposed subjects of the second stage were enrolled in the third stage of the study when they were exposed to fire smoke and a 